Dhaka Univ. J. Biol. Sci. 25(2): 139-148, 2016 (July)

\title{
CULTURE, REPRODUCTION AND EMBRYOGENESIS OF WILD ZEBRAFISH (DANIO RERIO) IN LABORATORY CONDITION
}

\author{
Md. Golam Rabbane*, Md. Feroz Ahmed, Mohammad Shamimul Alam ${ }^{1}$ \\ AND Md. MOTAHER Hossain² \\ Department of Fisheries, University of Dhaka, Dhaka-1000, Bangladesh
}

Key words: Culture, Reproduction, Embryogenesis, Danio rerio

\begin{abstract}
Zebrafish (Danio rerio: Hamilton, 1822) is a well-known model organism of biological research. Generally it is found in the fresh water ponds. However, the culture, breeding and embryonic development of wild D. rerio of Bangladesh is scarcely represented in the literature. Therefore, a laboratory experiment was conducted to study these aspects of local zebrafish. Water quality parameters for adult fish husbandry system were recorded. These were temperature $\left({ }^{\circ} \mathrm{C}\right) 29.18 \pm$ 1.53, pH $7.55 \pm 0.144$, TDS (ppm) $225 \pm 11.136$, (ORP) $48.93 \pm 26.04$, DO (ppm) $1.24 \pm$ 0.591 , conductivity $(\mathrm{mS} / \mathrm{cm}) 0.450 \pm 0.022$, are resistivity $(\mathrm{M} \Omega \mathrm{\iota cm}) 0.0026 \pm 0.00049$ for adult fish tanks. The parameters obtained from larvae rearing ranks were temperature $\left({ }^{\circ} \mathrm{C}\right) 29.56 \pm 0.777, \mathrm{pH} 7.73 \pm 0.421, \mathrm{TDS}(\mathrm{ppm}) 198.33 \pm 39.627,(\mathrm{ORP})$ $51.37 \pm 17.387, \mathrm{DO}(\mathrm{ppm}) 2.02 \pm 0.694$, conductivity $(\mathrm{mS} / \mathrm{cm}) 0.397 \pm 0.079$, resistivity $(\mathrm{M} \Omega \mathrm{cm}) 0.0026 \pm 0.00044$. After one month of rearing, adult male and female fishes were selected for natural breeding and spawning and obtained $87.5 \pm$ $7.72 \%$ spawning success, $96.83 \pm 0.81 \%$ fertilization rate and $94.89 \pm 0.27 \%$ hatching rate. The embryonic development for zygote, cleavage, blastula, gastrula, segmentation and pharyngula periods were observed and obtained proper development for each state at $28.5^{\circ} \mathrm{C}$. The survival rate of hatchlings was $10-20 \%$ up to 20 days post fertilization. The higher spawning success, fertilization rate, hatching rate and survival rate indicate the possibility and potentiality of culturing zebrafish in laboratory conditions and could be established as a model animal for Bangladeshi researchers.
\end{abstract}

\section{Introduction}

Zebrafish (Danio rerio: Hamilton, 1822) is a tropical freshwater fish, occurs in Bangladesh, India, Pakistan, Nepal and Myanmar. Zebrafish are widely found in irrigation ditches, rice fields, fish ponds, rivers, and fast flowing hill streams ${ }^{(1)}$.

\footnotetext{
*Author for correspondence: <rabbane@univdhaka.edu>. ${ }^{1}$ Department of Zoology, University of Dhaka, Dhaka-1000, Bangladesh. ${ }^{2}$ Department of Fisheries Technology and Quality Control, Sylhet Agriculture University, Bangladesh.
} 
Since 1930s, the zebrafish has been used as a classical developmental and embryological model. Subsequently, it has been widely used as a vertebrate research organism primarily for developmental genetics, and increasingly for toxicological and environmental monitoring, cancer, aging, neurophysiology, biomedicine and genetic diseases(2). A substantial amount of research has been conducted by using zebrafish compared to other fish species like medaka, stickleback, tilapia, seabass, salmon, etc. (Fig. 1). Unfortunately, the scientific culture and breeding technique of this model animal is poorly developed in Bangladesh. A few studies have been conducted on distribution, habitat and population genomics of wild zebrafish of Bangladesh ${ }^{(3-4)}$. Knowledge of zebrafish reproduction and embryonic development is essential for designing standard experiments involving this important model animal. However, culture, reproduction and embryonic development of native zebrafish in laboratory condition are yet to be reported from Bangladesh. So, the objectives of the current study were culture, breeding and embryogenesis of wild zebrafish at laboratory condition.

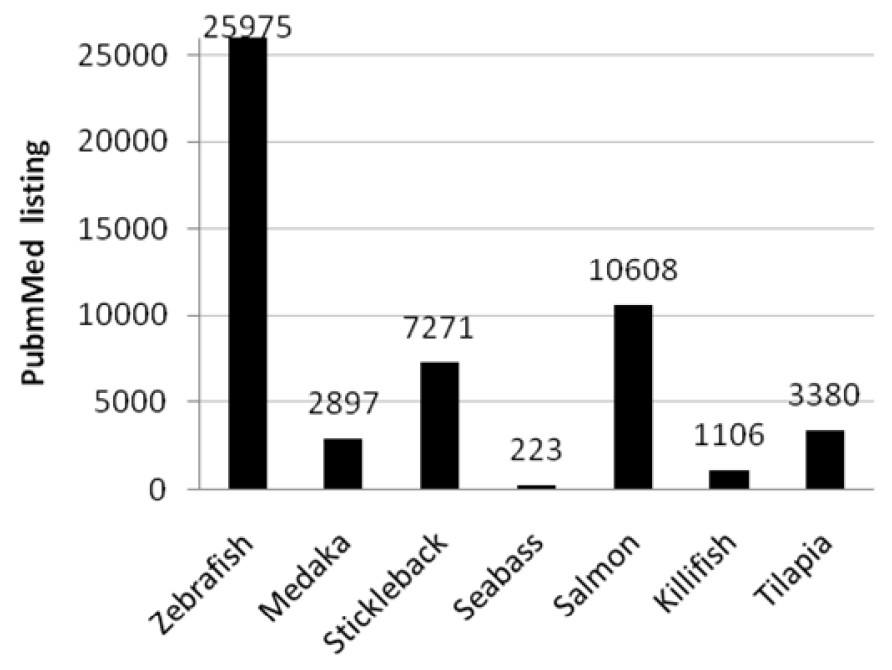

Fig. 1. The contribution of zebrafish in research in comparison with other fish reported in Pubmed (NCBI) References in year 2015. The term like 'zebrafish' and the year "2015" were used for searching in Pubmed.

\section{Materials and Methods}

In June 2015, a total of 50 wild Zebrafish were collected from the ponds of Dhola, Trisal upazila, Mymensingh, Pasmail, Dadar upazila, Rangpur district, and aquarium shops of Kataban market, Dhaka. The collected zebrafish were housed in a 5 litres tank filled with tap water in the Department of Fisheries, University of Dhaka for a period of 45 days. Density of fish was 10 adults per culture tank without counting males and 
females at this stage. The water parameters like temperature, $\mathrm{pH}$, total dissolved solids (TDS), oxidation reduction potential (ORP), dissolved oxygen (DO), conductivity and resistivity were recorded once during the whole study by using a multiparameter kit (HI 9828 multiparameter, HANNA Instruments, Woonsocket RI-USA). Two third of the fish tanks were filled with clean tap water. Condition of fishes was observed once daily. Tanks (1200 cubic inches) were cleaned regularly by siphoning and replaced with new water.

Adult fish, $2.77 \pm 0.19 \mathrm{~cm}$ (mean $\pm \mathrm{Sd}$ ) were fed commercial dry pellet (TetraBits ${ }^{\circledR}$ Complete, Tetra $\mathrm{GmbH}$, Germany) twice per day, occasionally supplemented with decapsulated live brine shrimp. The nutrients composition of the commercial dry pellet was protein $47.5 \%$, oil $6.5 \%$, ash $10.5 \%$, moisture 6\%; additives: vitamin A $29770 \mathrm{IU} / \mathrm{kg}$, vitamin D $31860 \mathrm{IU} / \mathrm{kg}$, vitamin E $200 \mathrm{mg} / \mathrm{kg}$, L-ascorbyl-2-polyphosphate $137 \mathrm{mg} / \mathrm{kg}$ (TetraBits ${ }^{\circledR}$ Complete, Tetra GmbH, Germany). GSL (USA) brine shrimp cysts were incubated at $30 \mathrm{ppt}$ salinity in the laboratory with proper oxygenation for the decapsulation. Fish were monitored daily for signs of distress, with extra water changes being performed when required.

After one month rearing, the maturity of zebrafish was confirmed by their external reproductive characteristics and breeding was performed in the laboratory. Firstly one litre capacity breeding tanks were prepared for each pair of breeders. At first a perforated plate was placed on the bottom of the plastic tank to prevent eggs from the cannibalism by the fish. The transparent separation sheet was also set up vertically at the middle position of the tank for the separation of male and female in the same tank. Then, the tank was filled with filtered tap water to maintain the quality of eggs. In the evening, a female and male in the ratio of $1: 1$ was kept in the breeding tank. They were kept separate by the separation sheet in the breeding tank. The tank was filled with about $2 \beta$ of filter water. The prepared tanks were kept in a safe place in a dark room with $14 \mathrm{hrs}$ dark and $10 \mathrm{hrs}$ light period because zebrafish breeding is strongly regulated by photoperiod. Finally, in the next morning the separation sheet was removed from the tank. The male and female (Fig. 2) came close to each other and the female then went under breeding mood. The eggs were dropped by the female and the male fertilized them by releasing milts. Since the zebrafish would consume eggs, the bottom was prepared by under plate to protect the future fertilized eggs from the cannibalism of the adults. The fertilized eggs were deposited on the floor of the breeding tank.

The breeding technique was repeated four times in a 8 to 10 days interval for each pair and the breeding performance indicators like spawning success, fecundity, fertilization rate, hatching rate and the survival rate of larvae up to 20 days post fertilization were calculated by using following formula(5):

$$
\text { Spawning success }(\%)=\frac{\text { No. of succeed spawning events per pair }}{\text { No. of observation per pair established }} \times 100 \% \text {. }
$$




$$
\begin{aligned}
& \text { Fertilization rate }(\%)=\frac{\text { No. of fertilized eggs }}{\begin{array}{c}
\text { Total no. of eggs produced during a } \\
\text { spawning event }
\end{array}} \times 100 \% \text {. } \\
& \text { Hatching rate }(\%)=\frac{\text { No. of hatched eggs }}{\begin{array}{c}
\text { Total no. of fertilized eggs produced } \\
\text { during a spawning event }
\end{array}} \times 100 \% \\
& \text { Survival rate }(\%)=\frac{\text { Final no. of larvae }}{\text { Initial no. of larvae }} \times 100 \% .
\end{aligned}
$$
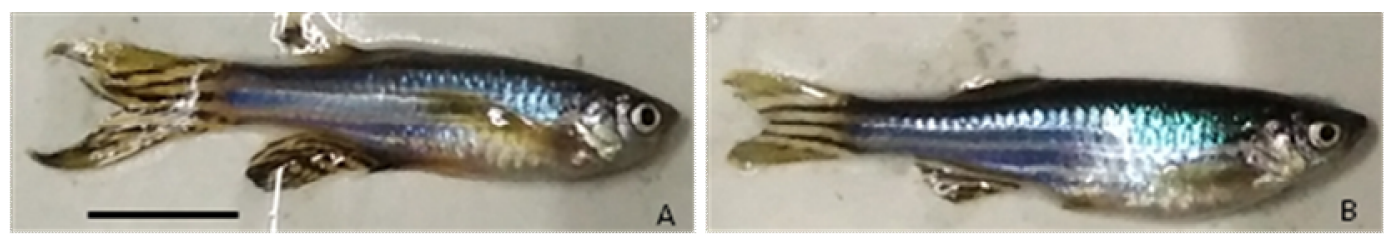

Fig. 2. Matured male (A) and female (B) zebrafish. Scale $=1 \mathrm{~cm}$.

Fecundity was calculated by counting the number of good eggs released by a female in a spawning event. Good eggs were determined by the observation of their external and internal morphology. The fertilized eggs were kept in an incubator (KB 53, Binder Inc USA) at $28.5^{\circ} \mathrm{C}$ where development time is abbreviated by the letter " $\mathrm{h}$ " and hours post fertilization is abbreviated as "hpf". A trinocular-microscope (MBL2000, Krüss, Germany) was used to study the embryogenesis of zebrafish at different developmental stages generally with transmitted illumination and high magnification (40x). The following stages were observed under microscope and photographs were taken: zygote period $(0-3 / 4 \mathrm{hrs})$, cleavage period $\left(3 / 4-2 \frac{1}{4} \mathrm{hrs}\right)$, blastula period $\left(2^{1 / 4}-5^{1 / 4} / \mathrm{hrs}\right)$, gastrula period (5 $1 / 4-10 \mathrm{hrs})$, segmentation period (10 - $24 \mathrm{hrs})$, pharyngula period ( $24-48 \mathrm{hrs}$ ), hatching period $(48-72 \mathrm{hrs})^{(6)}$.

The data of spawning success, fecundity, fertilization, hatching success and survival rate are presented as mean \pm standard error of the mean (SEM). Water quality parameters data are shown as mean \pm standard deviation (Sd). A one-way analysis of variance (ANOVA) was performed to detect significant differences $(\mathrm{p}<0.05)$ between the pairs by using SPSS software (Version 20.0. Armonk, NY : IBM Corp).

\section{Results and Discussion}

Water quality parameters were almost in acceptable range throughout the culture period. Table 1 shows the water quality parameters of adult and larval rearing tanks 
where temperature $26.18 \pm 1.53^{\circ} \mathrm{C}$ was recorded for adult tank and $27.56 \pm 0.777^{\circ} \mathrm{C}$ for larvae tank. The highest temperature $\left(30.90^{\circ} \mathrm{C}\right)$ was recorded and the lowest $\left(27.97^{\circ} \mathrm{C}\right)$ was found when rearing adult fish. Matthews et al. ${ }^{(7)}$ recommended that the appropriate wider range of temperature for zebrafish as $24-30^{\circ} \mathrm{C}$. But the maintenance temperature of zebrafish at laboratory condition is $28.5^{\circ} \mathrm{C}$ recommended by Westerfield ${ }^{(8)}$. Cortemeglia et al.(9) indicates that zebrafish have a maximal thermal tolerance range of 6.7 - $41.7^{\circ} \mathrm{C}$. The $\mathrm{pH}$ was $7.55 \pm 0.144$ and $7.73 \pm 0.421$ for adult and larval tanks, respectively where TDS was $225 \pm 11.136$ and $198.33 \pm 39.627$, respectively. Timmons et al. (10) stated that most teleost fish can tolerate a wider $\mathrm{pH}$ range from 6 to 9.5, it is normally practical to maintain most freshwater fish at a $\mathrm{pH}$ in the $7-8$ range to promote better condition of filters and stable water quality.

Table 1. Water quality parameters of adult zebrafish tanks and larval rearing tanks (mean $\pm \mathrm{Sd}$ ).

\begin{tabular}{lccccccc}
\hline Tank & $\begin{array}{c}\text { Temp. } \\
\left({ }^{\circ} \mathrm{C}\right)\end{array}$ & $\mathrm{pH}$ & $\begin{array}{c}\text { TDS } \\
(\mathrm{ppm})\end{array}$ & ORP & $\begin{array}{c}\text { DO } \\
(\mathrm{ppm})\end{array}$ & $\begin{array}{c}\text { Conductivity } \\
(\mathrm{mS} / \mathrm{cm})\end{array}$ & $\begin{array}{c}\text { Resistivity } \\
(\mathrm{M} \Omega \mathrm{cm})\end{array}$ \\
\hline Adult & 26.18 & 7.55 & 225 & 48.93 & 1.24 & 0.450 & 0.0026 \\
& \pm 1.53 & \pm 0.144 & \pm 11.136 & \pm 26 & \pm 0.591 & \pm 0.02 & \pm 0.00049 \\
Larva & 27.56 & 7.73 & 198.33 & 51.37 & 2.02 & 0.397 & 0.0026 \\
& \pm 0.777 & \pm 0.421 & \pm 39.62 & \pm 17.3 & \pm 0.694 & \pm 0.08 & \pm 0.00044 \\
\hline
\end{tabular}

The mean DO was $1.24 \pm 0.591$ and $2.02 \pm 0.694 \mathrm{ppm}$ for adult and larval tanks, respectively. DO is very important water quality parameter for fish culture because low levels of DO are responsible for higher fish mortalities in culture than any other water quality parameters ${ }^{(10-11)}$. The DO requirements of zebrafish have not been calculated yet. Popma and Masser ${ }^{(12)}$ said that a number of tropical fish species, such as tilapia are tolerant of lower levels of dissolved oxygen, and it may likely that zebrafish fall into this group, given that they are likely to encounter poor-oxygen habit in nature(12). The TDS of adult fish tanks $(225 \pm 11.136 \mathrm{ppm})$ was higher than that of larval tanks $(198.33 \pm 39.627)$. This is because the adult fish releases more waste products than larvae. Another cause may be the wastage of commercial feed in adult fish tanks. The conductivity and Resistivity of adult fish tank were $(\mathrm{mS} / \mathrm{cm}) 0.450 \pm 0.02$ and $(\mathrm{M} \Omega \mathrm{cm}) 0.0026 \pm 0.00049$ respectively whereas for larval tank $(\mathrm{mS} / \mathrm{cm}) 0.397 \pm 0.08$, and $(\mathrm{M} \Omega \mathrm{cm}) 0.0026 \pm 0.00044$ respectively recorded. Wooton(13) stated that growth rate, quality, number of offspring and survival rate will be decreased in captive or sub-optimal condition where more energy is necessary to maintain homeostasis rather than gamete production, growth and immune system. So, the determination of water quality is necessary in captive condition and the recorded parameters were in almost acceptable range throughout the culture time. 
Breeding performance indicator is shown in Table 2 where spawning success, fecundity, fertilization rate, hatching rate and survival rate of larvae were calculated as $87.5 \pm 7.72(\%), 307.5 \pm 45.87,96.83 \pm 0.81(\%), 94.89 \pm 0.27(\%)$ and $15 \pm 4.5(\%)$, respectively. A preliminary evaluation on the effects of feeds on the reproductive performance of zebrafish (Danio rerio) was conducted by Gonzales(5) and he found that highest $94.44 \%$ spawning success for (krill-flake mix) feed and lowest $61.11 \%$ spawning success for (krillflake mix + AP hatch 300) feed. He also received highest (340) and lowest (191) fecundity whereas this experiment obtained highest (450) and lowest (265) fecundity. Growth and reproductive performance mainly depends on the nutrient digestibility and nutritional composition of different diets of cultivated fish ${ }^{(14)}$.

Table 2. Reproductive performance of zebrafish.

\begin{tabular}{lcc}
\hline Breeding performance & Mean \pm SEM $(\mathrm{n}=16)$ & P value \\
\hline Spawning success $(\%)$ & $87.5 \pm 7.72$ & - \\
Fecundity & $307.5 \pm 45.87$ & 0.728 \\
Fertilization rate $(\%)$ & $96.83 \pm 0.81$ & 0.839 \\
Hatching rate $(\%)$ & $94.89 \pm 0.27$ & 0.789 \\
\hline
\end{tabular}

Goolish et al. (15) showed that the survival of larva was $84.3 \%$ in a daily three times feeding with dried egg yolk in controlled way. Average survival among treatment groups in the study by Önal and Langdon ${ }^{(16)}$ ranged from $40-98 \%$ for a similar time period, with the most excellent performance resulting from a diet of $40 \%$ GAB (commercial larval feed encapsulated in a gelatin-alginate bead) and 60\% Artemia nauplii. The present study observed the rate of survival of larva $15 \pm 4.5$ (\%). Lower rate of survival could be due to feeding frequency. In the present study, larval feeding frequency was twice daily whereas feeding frequency was reported thrice daily(15).

Initial attempts to rear zebrafish fry following laboratory protocols detailed in 'The Zebrafish Book'(8) proved very time consuming and resulted in extremely high larval mortality $(90-100 \%)$. So the result was similar, with this protocol. The fertilized eggs were incubated at $28.5^{\circ} \mathrm{C}$. Kimmel et al.(6) described that fertilized eggs develop normally at the temperature between 25 and $33^{\circ} \mathrm{C}$, but mortality and abnormality occurs below or higher level of these temperatures.

The first stage of embryogenesis is called zygote period and lasted for 45 minutes. In this stage the chorion or egg shell swelled and lifted away from the newly fertilized egg (Fig. 3A). Fertilization also induced cytoplasmic activities. Yolk free cytoplasm began to segregate toward the animal pole and this process continued up to early cleavage stages (1 hr).

Cleavage period started just after finishing zygote period and lasted for $2.15 \mathrm{hrs}$. Total 64 cells formed during this period. According to Kimmel et al. ${ }^{(6)}$ cleavage stage is 
divided into several substages like 2-cell, 4-cell, 8-cell, 32-cell and 64-cell stages. According to Kimme1 and Law ${ }^{(17)}$, the cytoplasmic divisions are meroblastic; on the basis of stage, it incompletely undercut the blastodisc, and the blastomeres, or a specific subset of them.
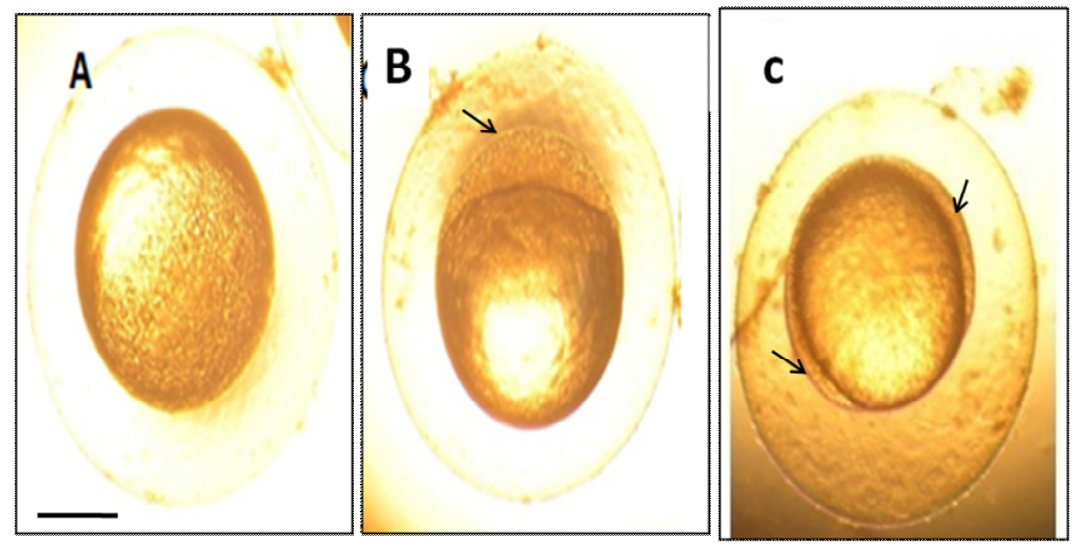

Fig. 3A. The zygote period (a newly fertilized egg). B: Dorsal views of embryo during the blastula period: Dome shape at $4.3 \mathrm{hpf}$ (arrow); C: The Gastrula period. Eighty per cent epiboly stage at $8.4 \mathrm{hpf}$ (arrow). Scale $=250 \mu \mathrm{m}$.

Cleavages ended after completing the sixth cycle (64-cell stage). The multiplication of the cell occurred in the animal pole of egg. The term blastula refer to the period when the blastodisc begins to look ball-like, at the 128-cell stage, or eighth zygotic cell cycle, and until the time of onset of gastrulation, cell cycle 14. Important processes occurred during this blastula period (Fig. 3B); the embryo entered mid-blastula transition (MBT), the yolk syncytial layer (YSL) formed, and epiboly began. Epiboly continued during the gastrulation period.

After blastula period, gastrula stage started at $5.15 \mathrm{hrs}$. Gastrula stage includes morphogenetic travel of involution, 50\%-epiboly stage, germ ring formation, embryonic shield stage, 75 to $90 \%$-epiboly stage and finally formation of tail bud (Fig. 3C). According to Strahle and Jesuthasan,(18) epiboly becomes visible due to functional microtubules and this process might be controlled by early-acting zygotic genes. Gastrula period continued up to $10 \mathrm{hrs}$ of fertilization. Formation of somites has started during segmentation period and appear successively in the trunk and tail region (Fig. 4A, B, C). Anterior somites formed earlier than posterior ones and a few somites developed more rapidly than later ones). Kimmel et al.(6) described this stage as tail bud stage because tail bud appears in the caudal end of the lengthening axis during whole period. Four somite stage, 17 and 25 somite stage are shown in Fig. 4A, B and C, respectively.

Pharyngula period started from $24 \mathrm{hrs}$ of fertilization when embryo becomes phyolotypic stage. Ballard(19) defined the term "pharyngula" to refer to the embryo that 
has developed to the phyolotypic stage, when it holds the classic vertebrate bauplan. The heart beat is visible is pharyngula state. This period with a clear notochord and a newly developed set of somites that expand to the end of a anal fin. Pharyngula period at 24, 32 and $44 \mathrm{hpf}$ are shown in Fig. 5A, B and C, respectively.

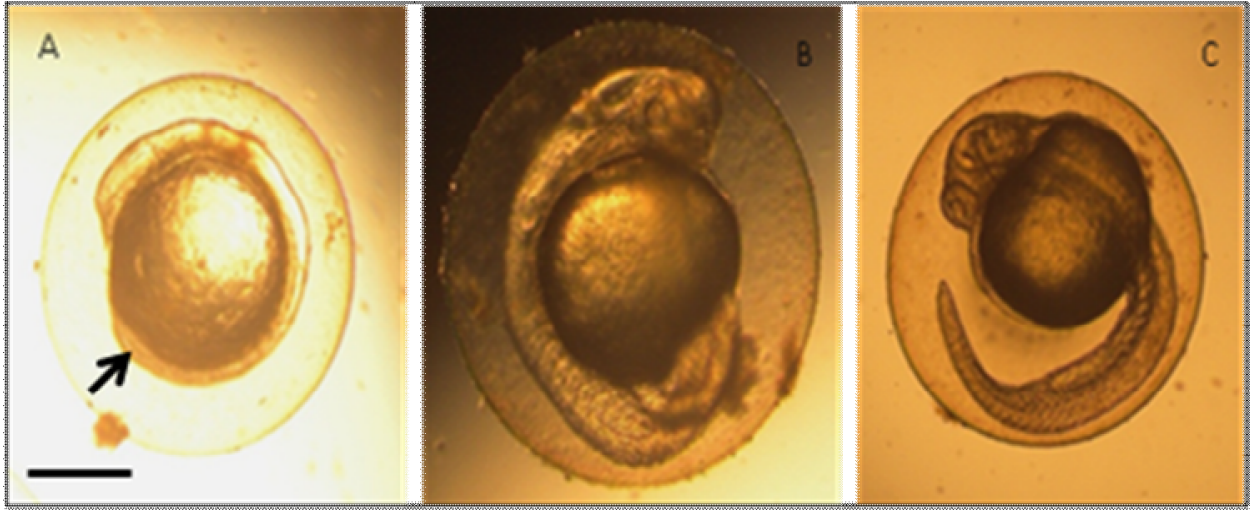

Fig. 4. Development during the segmentation period. A: Four-somite stage (11.5 hpf), tail bud (arrow). B: Seventeen-somite stage (18 hpf). C: Twenty-five somite stage (24 hpf). Scale $=250 \mu \mathrm{m}$.
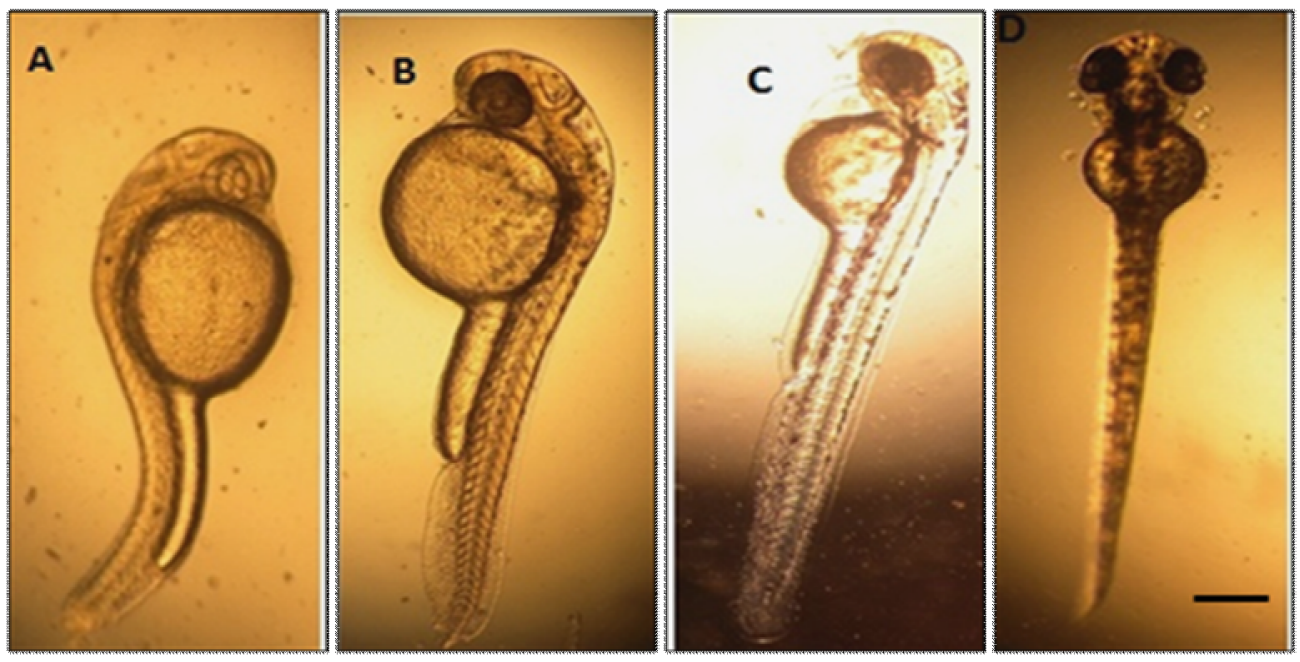

Fig. 5A. Pharyngula stage at $24 \mathrm{hpf}$. B: Pharyngula stage at $32 \mathrm{hpf}$. C: Pharyngula stage at $44 \mathrm{hpf}$.

D: Development during the hatching period of embryogenesis, protruding-mouth stage (72 hpf). Scale $=250 \mu \mathrm{m}$.

The larvae started to hatch from $46 \mathrm{hrs}$ of fertilization. The chorion bursts and the larvae came out into the surrounding water. Morphogenesis is almost finished in this stage. Mouth and pectoral fin development occurred in hatching stage (Fig. 4D).

Fujimura and Okada(20) also reported total 18 stages for Nile tilapia (Oreochromis niloticus), which were grouped into seven periods named the zygote, cleavage, blastula, 
gastrula, segmentation, pharyngula and hatching. However, the difference was found in larval hatching. In the present study, larval hatching started after $46 \mathrm{hpf}$ whereas, in their study, after $90 \mathrm{hpf}$.

Findings of the present study indicate that the spawning success, fertilization rate and developmental stage were satisfactory under laboratory condition and may play role as an important vehicle of culture, breeding and embryogenesis studies of zebrafish. Hence, the data might be useful in future study of zebrafish as a model animal in laboratory research in Bangladesh.

\section{Acknowledgement}

The work was conducted with the financial assistance of the University Grants Commission of Bangladesh (UGC).

\section{References}

1. Bhat A 2003. Diversity and composition of freshwater fishes in streams of Central Western Ghats, India. Environ. Biol. Fishes 68: 25-38.

2. Graham JL, DC Peter and JL Graham 2007. Animal models of human disease: zebrafish swim into view. Nature Reviews, Genetics 8: 353-367.

3. Spence R, MK Fatema, M Reichard, KA Huqk, MA Wahab, ZF Ahmed and C Smith 2006. The distribution and habitat preferences of the zebrafish in Bangladesh. Journal of Fish Biology 69: 1435-1448.

4. Whiteley AR, A Bhat, E P Martins, RL Mayden, M Arunachalam, S Uusi-heikkila, ATA Ahmed, J Shrestha, M Clark, D Stemple and L Bernatchez 2011. Population genomics of wild and laboratory zebrafish (Danio rerio). Molecular Ecology 20: 4259-4276.

5. Gonzales JM 2012. Preliminary Evaluation on the Effects of Feeds on the Growth and Early Reproductive Performance of Zebrafish (Danio rerio). Journal of the American Association for Laboratory Animal Science 51(4): 412-417.

6. Kimmel CB, WW Ballard, SR Kimmel, B Ullmann and TF Schilling 1995. Stages of embryonic development of zebrafish. Developmental Dynamics 203: 253-310.

7. Matthews MT, B Trevarrow and BJ Matthews 2002. A virtual tour of the guide for zebrafish users. Lab Anim. 31: 34-40.

8. Westerfield M 1995. The Zebrafish Book: A Guide for the Laboratory Use of Zebrafish (Danio rerio), 3rd edition, University of Oregon Press, Eugene, OR. pp .385.

9. Cortemeglia C and TL Beitinger 2005.Temperature tolerances of wildtype and red transgenic zebra danios. Trans. Am. Fish. Soc. 134: 1431-1437.

10. Timmons MB, JM Ebeling, JM Wheaton, ST Summerelt and ST Vinci 2002. Recirculating Aquaculture Systems.( $2^{\text {nd }}$ edition). Cayuga Aqua Ventures, Ithaca, N.Y. pp .757.

11. Boyd CE 1979. Water Quality in Warm Water Fish Ponds. Alabama Agricultural Experiment Station, Auburn University, Alabama. pp. 359.

12. Popma T and M Masser 1999. Tilapia: Life history and biology. Southern Regional Aquaculture Center Publication, vol. 283. Stoneville, MS, pp. 4. 
13. Wooton R.J 1998. The Ecology of Teleost Fishes, 2nd edition. Chapman and Hall, London. pp. 404.

14. Kaushik S, I Georga and G Koumoundouros 2011. Growth and body composition of zebrafish (Danio rerio) larvae fed a coumpound feed from first feeding onward: toward implications on nutrient requirements. Zebrafish 8: 87-95.

15. Goolish EM, K Okutake and S Lesure 1999. Growth and Survivorship of larval zebrafish Danio rerio on processed diets. N. Am. J. Aquac. 61: 189-198.

16. Önal U and CJ Langdon 2000. Characterization of two microparticle types for delivery of food to altricial fish larvae. Aquac.Nutr. 6: 159-170.

17. Kimmel CB and RD Law 1985. Cell lineage of zebrafish blastomeres. I. Cleavage pattern and cytoplasmic bridges between cells. Dev. Biol. 108: 78-85.

18. Strahle U and S Jesuthasan 1993. Ultraviolet irradiation impairs epiboly in zebrafish embryos: evidence for a microtubule-dependent mechanism of epiboly. Development 119: 909-919.

19. Ballard WW 1981. Morphogenetic movements and fate maps of vertebrates. Am. Zool. 21: 391399.

20. Fujimura K and N Okada 2007. Development of the embryo, larva and early juvenile of Nile tilapia Oreochromis niloticus (Pisces: Cichlidae). Developmental staging system. Develop. Growth Differ. 49: 301-324.

(Manuscript received on 9 March, 2016; revised on 22 July, 2016) 